\title{
Clinical role of obinutuzumab in the treatment of naive patients with chronic lymphocytic leukemia
}

\author{
This article was published in the following Dove Press journal: \\ Biologics: Targets and Therapy \\ 16 February 2015 \\ Number of times this article has been viewed
}

\author{
Sonia Cerquozzi' \\ Carolyn Owen ${ }^{2}$ \\ 'Department of Hematology, \\ University of Calgary, ${ }^{2}$ Department \\ of Hematology, Tom Baker Cancer \\ Centre, Calgary, AB, Canada
}

Correspondence: Carolyn Owen Department of Hematology, University of Calgary, South Tower Room 603, 140329 Street NW, Foothills Medical Centre, Calgary, AB, T2N 2T9, Canada $\mathrm{Tel}+\mathrm{I} 4039443265$

Fax +I 4039448352

Email carolyn.owen@

albertahealthservices.ca

\begin{abstract}
The introduction of targeted therapy against $\mathrm{CD} 20^{+}$with the monoclonal antibody rituximab has dramatically improved the survival of B-cell non-Hodgkin lymphoma including chronic lymphocytic leukemia (CLL)/small lymphocytic lymphoma. Unfortunately, CLL remains incurable with chemoimmunotherapy, with many patients having refractory or relapsing disease after rituximab-containing therapy. Obinutuzumab (GA101) is a novel humanized Type II antiCD20 monoclonal antibody that has been investigated and compared to rituximab. Here, we provide an overview of obinutuzumab, including its mechanisms of action, preclinical data, and Phase I to III clinical studies. Preclinical data illustrate obinutuzumab's higher potency compared to rituximab through antibody-dependent cellular cytotoxicity and direct cell death. Recently, the CLL11 study presented a significant benefit from obinutuzumab chemoimmunotherapy and supports its use for treatment-naive unfit CLL patients. Herein, we review that obinutuzumab is both a safe and effective alternative to rituximab.
\end{abstract}

Keywords: CLL, GA101, antibody, CD20

\section{Introduction}

Chronic lymphocytic leukemia (CLL) is the most common lymphoproliferative disorder in the Western world and accounts for approximately $11 \%$ of all hematologic malignancies. ${ }^{1}$ The majority of patients diagnosed with CLL are older than 70 years of age. ${ }^{2}$ The natural history of CLL is variable, and we now have a better understanding of the pathophysiology of the disease, which has led to identification of prognostic factors and effective targeted therapies. ${ }^{3}$ Treatment is recommended for symptomatic disease such as progressive cytopenias, massive splenomegaly, bulky adenopathy, and constitutional symptoms. ${ }^{4}$ The choice of treatment depends on factors such as clinical stage of disease, patient fitness, cytogenetic abnormalities, prior treatments, and responses to previous therapy. ${ }^{3}$ The degree of frailty of older CLL patients and the presence of comorbid conditions must also be taken into account in making treatment decisions. Tools such as the Cumulative Illness Rating Scale (CIRS), which measures the burden and severity of chronic disease, have been used to determine patient suitability for treatment. ${ }^{5}$ CLL patients can also be categorized as "fit" based on factors such as good performance status (ECOG 0-1), good renal function with creatinine clearance $>70 \mathrm{~mL} / \mathrm{min}$, and a CIRS score of $<6 .{ }^{6-8}$ Those who are "fit" are considered for standard intensive therapies, whereas those less "fit" warrant reduced-intensity treatment, and the most frail patients with marked comorbidities will likely have no benefit from CLL chemotherapy. ${ }^{5,6}$

Overall, the treatment of CLL has rapidly evolved over the past few decades. 
The initial development of the anti-CD20 monoclonal antibody $(\mathrm{mAb})$ rituximab revolutionized the treatment of $\mathrm{CD} 20^{+}$lymphoproliferative disorders including most B-cell non-Hodgkin lymphomas (NHLs) and CLL. Early results of rituximab monotherapy in CLL revealed low response rates. ${ }^{9}$ However, addition of rituximab to fludarabine plus cyclophosphamide significantly improved progression-free survival (PFS) and overall survival (OS) in young, fit, previously untreated CLL patients, establishing this as the gold standard chemotherapy for younger, fit CLL patients. ${ }^{10}$ In elderly CLL patients with comorbidities, the addition of rituximab to chlorambucil also improved PFS and complete response (CR) rates compared to chlorambucil monotherapy but did not result in an OS advantage. ${ }^{11}$ Despite the benefits of rituximab, all patients will eventually relapse after rituximabcontaining immunochemotherapy., ${ }^{9}{ }^{12}$ As a result, great efforts have been made to develop superior therapeutic options.

Several emerging therapies are under investigation, including immunomodulatory agents (eg, lenalidomide), Bruton tyrosine kinase inhibitors (eg, ibrutinib), phosphatidylinositol-3 kinase (PI3K) inhibitors (eg, idelalisib), BCL-2 family anti-apoptotic protein inhibitors (eg, ABT-199), and next-generation monoclonal antibodies. ${ }^{3}$ The majority of the novel anti-CD20 mAbs are Type I antibodies, including ofatumumab, which has been approved for use in fludarabine and alemtuzumab refractory CLL and was recently approved for frontline therapy in combination with chlorambucil. ${ }^{13}$ Obinutuzumab is the only glycoengineered Type II mAb that has been evaluated clinically, which consequently has led to its recent Food and Drug Administration approval based on its superior results as frontline therapy. ${ }^{14}$ The objective of this review is to illustrate the role of obinutuzumab in the treatment of therapy-naive CLL patients.

\section{Pharmacology}

CD20 is a cell surface molecule expressed in high levels in B cells. CD20 plays a role in the generation of T-cellindependent antibody response and regulates early steps of B-lymphocyte activation. Most B cells express CD20 on their surface, and the antigen is not shed or internalized in resting cells. Moreover, CD20 is not found on stem cells, precursor cells, or plasma cells, which makes it an ideal therapeutic target for B-cell malignancies. ${ }^{15}$

\section{Type I/II antibody classification}

The mechanisms of cellular cytotoxicity of Type I and Type II antibodies differ, and the exact mechanisms of each are controversial. Type I antibodies cause translocation of
CD20 into lipid rafts (insoluble lipid domains) within the cell membrane, which results in strong complement $(\mathrm{C} 1 \mathrm{q})$ binding in vitro and efficient induction of complement-dependent cellular cytotoxicity (CDC). ${ }^{16}$ The in vivo mechanism of Type I antibodies is controversial, but most studies suggest CDC activity ${ }^{17-23}$ and antibody-dependent cellular cytotoxicity. ${ }^{24,25}$ Type II antibodies do not function via stabilization of lipid rafts, but rather, CD20 remains distributed across the B-cell surface and in vitro complement binding is weaker. As a result, obinutuzumab is 10- to 1,000 -fold less potent than rituximab and ofatumumab at $\mathrm{CDC} .{ }^{26}$

However, based on the unique binding of Type II antibodies to CD20 epitopes, these mAbs more potently evoke direct cell death (DCD) compared to Type I mAbs. ${ }^{27}$ Obinutuzumab has a modified elbow hinge region that leads to superior antigen binding and increased DCD. ${ }^{27,28}$ The glycoengineered Fc region also enhances the affinity (50-fold higher than nonengineered antibodies) for the FcyRIIIa (CD16) on immune effector cells, which leads to higher antibody-dependent cellular cytotoxicity activity that is 100 -fold greater than rituximab and ofatumumab in preclinical studies. ${ }^{26,28-30}$ Additional in vitro studies demonstrate that obinutuzumab can activate neutrophils via Fc $\gamma$ RIIIb (CD16B) and mediate phagocytosis better than rituximab. ${ }^{31}$ Interestingly, several studies have shown that DCD induction by obinutuzumab occurs through a nonapoptotic process involving actin rearrangement, lysosome rupture, and generation of reactive oxygen species..$^{32,33}$ Further understanding of this cell death mechanism is warranted since other studies illustrated mitochondrial involvement via caspase activity during obinutuzumab-induced cell death, a mechanism that did not involve reactive oxygen species. Regardless, it appears that the mechanisms of DCD of obinutuzumab is unique and distinctive from Type I mAbs and given that this activity does not depend on classical apoptotic pathways, it is suggested that obinutuzumab may be able to overcome apoptosis resistance mechanisms that are key to chemotherapy resistance. ${ }^{26,32,34}$

Several putative mechanisms of rituximab resistance have been summarized in a prior review ${ }^{35}$ and include CD20-mAb complex internalization or CD20 "shaving" that involves removal of rituximab/CD20 complexes from the B-cell surface via monocytes through a mechanism known as trogocytosis, leading to a reduced mAb half-life. ${ }^{36-38}$ Type II $\mathrm{mAbs}$ do not induce CD20 internalization and thus can avoid this resistance strategy. Additional resistance mechanisms to rituximab include aberrant lipid raft composition of malignant B cells, ${ }^{35,39}$ complement depletion, ${ }^{15,40}$ polymorphisms of the CD16 receptor, ${ }^{41,42}$ downregulation of proapoptotic 
proteins,${ }^{43}$ and reduction of CD20 expression following rituximab treatment. ${ }^{44}$ Obinutuzumab is less affected by most of these resistance mechanisms, which may explain its increased potency. ${ }^{35}$

\section{Pharmacokinetics}

Pharmacokinetic data were analyzed in Phase I/II studies of obinutuzumab monotherapy and are also summarized in previous reviews. ${ }^{35,45}$ The elimination of obinutuzumab is complex and involves both a linear clearance and timedependent (nonlinear) clearance pathway. Based on population pharmacokinetic studies, the steady-state mean volume of distribution is approximately $3.8 \mathrm{~L}$ with an elimination half-life of 28 days and terminal clearance of $0.09 \mathrm{~L} /$ day. The elimination of obinutuzumab is likely target-mediated drug disposition. ${ }^{46,47}$ The relationship between pharmacokinetics and clinical response and/or tumor burden could not be concluded based on Phase I/II trials due to small population numbers. However, the Phase II study reported disappointing response rates in patients with higher tumor burden, suggesting that dosing schedules may be very important for obinutuzumab's efficacy. ${ }^{48}$ Of note, recovery of B-cell count occurred in the majority of patients 24 months following their last dose of obinutuzumab. ${ }^{48}$ Insufficient data exist on the effect of severe renal or hepatic impairment; however, no modifications are expected since monoclonal antibodies are metabolized via ubiquitous proteolytic enzymes. ${ }^{46,47}$ Further pharmacokinetic data are anticipated with the currently ongoing GAGE study, which is comparing the efficacy and safety of obinutuzumab dosed intravenously at $1,000 \mathrm{mg}$ vs 2,000 mg. Preliminary results at week 32 describe overall response rates (ORRs) of $48.8 \%$ and $66.7 \%(P=0.0779)$ among patients receiving $1,000 \mathrm{mg}(\mathrm{n}=41)$ and $2,000 \mathrm{mg}$ intravenous infusions $(\mathrm{n}=39)$, respectively. Serious adverse events occurred in $20 \%(1,000 \mathrm{mg})$ vs $18.4 \%(2,000 \mathrm{mg})$ of patients with none leading to discontinuation of therapy. ${ }^{49}$

\section{Preclinical studies}

Whole-blood assays demonstrate that obinutuzumab results in superior B-cell depletion in comparison to rituximab in both healthy and leukemic B cells. ${ }^{22,26,28,31,50}$ The efficacy of obinutuzumab was also confirmed in animal models. In cynomolgus monkeys, both obinutuzumab and rituximab depleted B cells from peripheral blood; however, depletion of B cells in the spleen and lymph nodes was greater with obinutuzumab. ${ }^{28}$ Obinutuzumab was also superior in the treatment of NHL in a variety of xenograft models even when compared to high doses of rituximab reaching up to $30 \mathrm{mg} / \mathrm{kg} \cdot{ }^{21,26,28}$ Obinutuzumab was also superior to both rituximab and ofatumumab when investigated as a second-line therapy in a SUDHL-4 DLBCL mouse model after prolonged treatment with rituximab to create a model of rituximab resistance. ${ }^{26,28}$ Combination studies with cyclophosphamide, ${ }^{21}$ bendamustine, fludarabine, chlorambucil, or cyclophosphamide/vincristine demonstrated that obinutuzumab chemoimmunotherapy was more efficacious than therapy including rituximab in those xenograft models. Obinutuzumab monotherapy was even as effective as rituximab combinations with bendamustine or fludarabine in some models. ${ }^{51}$

\section{Clinical studies Phase I/II}

Phase I trials of obinutuzumab monotherapy have been conducted in patients with CLL and NHL. This review focuses on obinutuzumab treatment in CLL, summarized in Table 1. Additional studies have been discussed in detail in prior reviews. ${ }^{35,45,52}$ An initial Phase I study evaluated the safety and clinical activity of escalating doses of obinutuzumab monotherapy over eight 21-day cycles with doses ranging from $50 / 100 \mathrm{mg}$ to $1,200 / 2,000 \mathrm{mg}$ intravenous in patients with relapsed/refractory NHL. No dose-limiting toxicities were detected with the majority of AEs being infusion-related reactions (IRRs) and hematologic toxicities. Most AEs were grade 1 or $2(86 \%)$ with $33 \%$ grade 3 or 4 events. IRRs were the most frequent AE, mostly isolated to first infusions and $98 \%$ were grade 1 or 2 reactions. Obinutuzumab achieved a best overall response of $43 \%$ with five CRs and four partial responses (PRs), ${ }^{53}$ in this heavily pretreated population. A subsequent Phase I study also including patients with relapsed/refractory NHL evaluated obinutuzumab induction monotherapy at doses of 200-2,000 mg intravenously weekly for 4 weeks, followed by 2 years of maintenance therapy in responders. Again, no dose-limiting toxicities were noted. The most common AE was IRR ( $73 \%$ all grades, $18 \%$ grade $3 / 4$ ), all related to first infusion, with only one IRR leading to treatment discontinuation due to hypoxia. Other grade 3-4 AEs included neutropenia, headache, and infection. At the end of induction, 5 (23\%) patients had PR and 12 (54\%) had stable disease with 8 patients (36\%) proceeding to maintenance therapy. The best overall response was $32 \%$ which included one CR and six PRs. ${ }^{54}$

A separate portion of the Phase I/II GAUGUIN study specifically examined obinutuzumab monotherapy in relapsed/refractory CLL. In the Phase I study, dose 
Table I Summary of trials evaluating the efficacy and safety of obinutuzumab in CLL

\begin{tabular}{|c|c|c|c|c|}
\hline Trial & $\begin{array}{l}\text { Study } \\
\text { design }\end{array}$ & $\begin{array}{l}\text { No of } \\
\text { subjects }\end{array}$ & Population & Obinutuzumab dose \\
\hline \multirow[t]{4}{*}{ GAUGUIN } & Phase I & 34 & $\begin{array}{l}\text { Relapsed/refractory } \mathrm{NHL} \\
(\mathrm{CLL}, \mathrm{n}=13)\end{array}$ & $\begin{array}{l}\text { Monotherapy: dose escalation ( } 400-2,000 \text { mg) } \\
\text { DI, 8, } 22 \text { Cycle I, DI Cycles 2-6 }\end{array}$ \\
\hline & Phase II & 40 & Relapsed/refractory iNHL & Flat dose: low (LD) and high (HD) \\
\hline & $(n=100)$ & 40 & Relapsed/refractory aNHL & LD: 400 mg DI + D8 Cycle I, 400 mg D I Cycles 2-6 \\
\hline & & 20 & Relapsed/refractory CLL & HD: I,600 mg DI + D8 Cycle I, 800 mg D I Cycles 2-6 \\
\hline \multirow[t]{2}{*}{ GAUSS } & Phase I & 22 & $\begin{array}{l}\text { Relapsed/refractory NHL } \\
(C L L n=5, S L L n=2)\end{array}$ & $\begin{array}{l}200-2,000 \mathrm{mg} \text { DI, D8, D22 q4 weeks } \times 6 \text { (DI } 50 \% \text { dose } \\
\text { reduced) } \\
\text { Maintenance: q3 months } \times 2 \text { years (in responders) }\end{array}$ \\
\hline & $\begin{array}{l}\text { Phase II } \\
(n=175)\end{array}$ & $\begin{array}{l}87 \\
88\end{array}$ & Relapsed/refractory iNHL & $\begin{array}{l}\text { Obinutuzumab }(\mathrm{O}) \text { vs rituximab }(\mathrm{R}) \text { : } \\
\text { O: } 1,000 \mathrm{mg} \text { weekly } \times 4 \text { then } \mathrm{q} 2 \text { months } \times 2 \text { years } \\
\text { (in responders) } \\
\text { R: } 375 \mathrm{mg} / \mathrm{m}^{2} \text { weekly } \times 4 \text { then } \mathrm{q} 2 \text { months } \times 2 \text { years } \\
\text { (in responders) }\end{array}$ \\
\hline GALTON & $\begin{array}{l}\text { Phase Ib } \\
(n=4 I)\end{array}$ & $\begin{array}{l}21 \\
20\end{array}$ & Relapsed/refractory CLL & $\begin{array}{l}\text { Chemoimmunotherapy: obinutuzumab with FC or B } \\
100 \text { mg DI, } 900 \text { mg D2, I,000 mg D8 and DI5 Cycle I, } 100 \text { mg } \\
\text { DI Cycle 2-6 + FC } \\
100 \text { mg DI, } 900 \text { mg D2, I,000 mg D8 and DI5 Cycle I, } \\
\text { I,000 mg DI, Cycle 2-6 + B }\end{array}$ \\
\hline CLLII & Phase III & 781 & $\begin{array}{l}\text { Untreated CLL in elderly/ } \\
\text { comorbidities }\end{array}$ & $\begin{array}{l}\text { Chemoimmunotherapy: Obinutuzumab + CLB } \\
\text { I,000 mg DI, 8, I5 Cycle I, I,000 mg D I Cycle 2-6 + CLB }\end{array}$ \\
\hline GAGE & Phase II & 80 & $\begin{array}{l}\text { Symptomatic, previously } \\
\text { untreated CLL }\end{array}$ & $\begin{array}{l}\text { Obinutuzumab } 100 \mathrm{mg} \text { DI, } 900 \mathrm{mg} \text { D2 I,000 mg D8, I5 of } \\
\text { Cycle I, I,000 mg DI Cycles 2-8 vs Obinutuzumab } 100 \mathrm{mg} \text { D I, } \\
900 \mathrm{mg} \text { D2, I,000 mg D3, 2,000 mg D8, I } 5 \text { of Cycle I, } \\
2,000 \mathrm{mg} \text { D I Cycles 2-8 }\end{array}$ \\
\hline
\end{tabular}

Abbreviations: aNHL, Aggressive non-Hodgkin lymphoma; B, bendamustine; CLB, chlorambucil; CLL, chronic lymphocytic leukemia; D, day; FC, fludarabine + cyclophosphamide; HD, high dose; iNHL, indolent non-Hodgkin lymphoma; LD, low dose; NHL, non-Hodgkin lymphoma; SLL, small lymphocytic lymphoma.

escalation of obinutuzumab (400-1,200 mg) was provided to $13 \mathrm{relapsed} /$ refractory CLL patients, and 20 additional CLL patients received a fixed dose of $1,000 \mathrm{mg}$ in the Phase II study. In both studies, all patients experienced $\geq 1 \mathrm{AE}$, most commonly IRR, neutropenia, lymphopenia, and thrombocytopenia with the majority of AEs $(82 \%)$ being grade $1-2$. Grade 4 AEs included neutropenia (15\%-38\%), febrile neutropenia $(5 \%-8 \%)$, and thrombocytopenia $(0 \%-15 \%)$. At study completion, several PRs were observed with an overall end-of-treatment response of $62 \%$ (Phase I) and 15\% (Phase II) and a best overall response of 62\% (Phase I) and 30\% (Phase II). The median PFS was 10.7 months with a median duration of response of 8.9 months. Based on these initial studies, obinutuzumab proved to be a safe and welltolerated therapy for relapsed/refractory CLL with modest activity as monotherapy, warranting further investigation as chemoimmunotherapy. ${ }^{48}$ The reasons for the less impressive response rates in the Phase II component of the study were predicted by the authors to relate to higher tumor burden in these patients. They hypothesized that higher doses of obinutuzumab might be required for such patients, an approach that is being investigated in the currently enrolling GAGE study. ${ }^{49}$
Results of the GAGE study were recently presented at the American Society of Oncology Annual Meeting and demonstrated high rates of $\mathrm{CR} / \mathrm{CRi}$ in patients receiving the higher 2,000-mg dose of obinutuzumab (compared to those receiving the standard dose of $1,000 \mathrm{mg}$ ). The subjects in the study were previously untreated patients with CLL, with the arms well balanced between the two cohorts. An ORR of $67 \%$ was observed in the higher dose group compared to $49 \%$ in the standard dose group with marked differences in CR/ CRi rates (21\% vs 5\%, respectively). These results suggest that single-agent obinutuzumab can have marked efficacy even in the absence of combination with chemotherapy. ${ }^{49}$

The GALTON Phase Ib study addressed the safety of obinutuzumab combination therapy, using investigator choice backbone chemotherapy with either fludarabine and cyclophosphamide (FC) or Bendamustine (B) for previously untreated CLL patients. Adverse events were not dose limiting, with the most common being IRRs that occurred with the first infusion. IRRs (all grades) were very common ( $~ 90 \%$ of patients) and occurred in both arms with slightly higher rates in the obinutuzumab-FC arm, in which $29 \%$ were grade 3-4. Additional grade 3-4 AEs were neutropenia and infection. The ORR was $62 \%$ including two CR in the 
obinutuzumab-FC arm vs $90 \%$ ORR in the obinutuzumab-B arm, which included four CRs. This study confirmed that obinutuzumab could be safely administered with standard chemotherapeutics for the treatment of previously untreated CLL patients. ${ }^{55}$

\section{Phase III}

CLL is predominantly a disease of the elderly, but until recently, older patients were grossly underrepresented in CLL clinical trials. The first completed Phase III study of obinutuzumab was conducted by the German CLL Study Group and focused on this older, frailer CLL population. A previous study by the same German CLL Study Group in a similar elderly CLL population had established chlorambucil (CLB) as an appropriate firstline therapy for older CLL patients. ${ }^{56}$ The CLL11 Phase III trial was a multicenter, randomized controlled, open-label study that enrolled 781 previously untreated CLL patients with comorbidities. This was a threearm, two-stage trial that assessed whether the addition of either rituximab or obinutuzumab could enhance the efficacy of chlorambucil monotherapy in this CLL population. The median age of the patients was 73 years with a median CIRS score of 8 , this being a very representative CLL population. Eighty-two percent of patients had more than three comorbidities and $27 \%$ had one or more coexisting conditions that were not well controlled at baseline. ${ }^{14}$

Patients were randomized to receive obinutuzumab plus chlorambucil (G-CLB) (stage 1, $\mathrm{n}=238$; stage 2, $\mathrm{n}=333$ ) or rituximab plus chlorambucil (R-CLB) (stage 1, $n=233$; stage $2, \mathrm{n}=330$ ) or chlorambucil alone (CLB) (stage 1, $\mathrm{n}=118$ ) for a total of six 28-day cycles. Chlorambucil was administered orally at $0.5 \mathrm{mg} / \mathrm{kg}$ on days 1 and 15 of each cycle. Obinutuzumab was administered intravenously at $1,000 \mathrm{mg}$ on days 1,8 , and 15 of cycle 1 and day 1 of cycles 2-6 while rituximab was given at a dose of $375 \mathrm{mg} / \mathrm{m}^{2}$ on day 1 of cycle 1 and $500 \mathrm{mg} / \mathrm{m}^{2}$ on day 1 of cycles $2-6$. Due to IRRs reported in the first $89 \%$ of patients receiving obinutuzumab, the first infusion was subsequently modified to be given as $100 \mathrm{mg}$ on day 1 then $900 \mathrm{mg}$ on day 2 of cycle 1 . This protocol amendment was in effect for the final 45 patients in the obinutuzumab arm of the study and was considered too small a population to make firm conclusions as to the effectiveness of the strategy in reducing IRRs. ${ }^{14}$

The primary endpoint of the study was PFS with secondary endpoints including response rates, OS, and minimal residual disease (MRD). A summary of results comparing chemoimmunotherapy with both anti-CD20 mAbs is shown in Table 2. The use of obinutuzumab with CLB (G-CLB) significantly prolonged PFS compared to both chlorambucil monotherapy (26.7 months vs 11.1 months, HR 0.18, $P<0.001)$ and R-CLB (26.7 months vs 15.2 months, HR 0.39, $P<0.001)$. The ORR was $77.3 \%$ in the obinutuzumab arm vs $65.7 \%$ in the rituximab arm and $31.4 \%$ for chlorambucil monotherapy. Higher CR rates occurred with G-CLB compared to R-CLB (22.3\% vs $7.4 \%, P<0.001)$, and CR was not achieved with chlorambucil monotherapy. ${ }^{14} \mathrm{OS}$ benefits were achieved with G-CLB compared to CLB (9\% death rate vs $20 \%$, HR $0.41, P=0.002$ ), but no significant OS benefit was noted for R-CLB compared to CLB or with G-CLB compared to R-CLB. MRD rates were markedly increased in the G-CLB arm compared to R-CLB (19.5\% vs $2.6 \%$ MRD in BM, 37.7\% vs 3.3\% MRD in blood, $P<0.001) .{ }^{14} \mathrm{MRD}$ has been found to be predictive of both PFS and OS based on the results in younger, fitter patients. ${ }^{57,58}$ No MRD negativity was achieved using chlorambucil alone. ${ }^{14}$

The most frequent AEs in the G-CLB arm included IRRs and infections. Grade 3-4 IRRs were higher in the G-CLB arm compared to R-CLB (20\% vs 4\%) during the first infusion with no further grade 3-4 IRRs in subsequent cycles and no deaths related to IRRs. Most infections were low grade, with grade 3-5 infections ranging from $11 \%$ to $14 \%$ and not differing among treatment groups.

Table 2 Summary of the efficacy and safety outcomes from the CLLII trial

\begin{tabular}{|c|c|c|c|}
\hline & $\begin{array}{l}\text { Chlorambucil + } \\
\text { rituximab } \\
(\mathrm{N}=321)\end{array}$ & $\begin{array}{l}\text { Chlorambucil + } \\
\text { obinutuzumab } \\
(\mathrm{N}=336)\end{array}$ & $P$ value \\
\hline \multicolumn{4}{|l|}{ Efficacy } \\
\hline Median PFS, months & 15.2 & 26.7 & $<0.001$ \\
\hline Median OS, months & NR & $N R$ & 0.09 \\
\hline ORR $(\%)$ & 65 & 78 & $<0.001$ \\
\hline CR rate $(\%)$ & 7 & 21 & $<0.001$ \\
\hline \multirow[t]{2}{*}{ MRD negative (\%) } & $2.6(\mathrm{BM})$ & $19.5(\mathrm{BM})$ & $<0.001$ \\
\hline & 3.3 (blood) & 37.7 (blood) & $<0.001$ \\
\hline \multicolumn{4}{|l|}{ Safety } \\
\hline $\begin{array}{l}\text { Overall grade } 3 \text { or } \\
\text { higher } A E\end{array}$ & 55 & 70 & \\
\hline $\begin{array}{l}\text { Infusion-related } \\
\text { reactions }\end{array}$ & 4 & 20 & \\
\hline Neutropenia & 28 & 33 & \\
\hline Thrombocytopenia & 3 & 10 & \\
\hline Infections & 14 & 12 & \\
\hline Tumor lysis syndrome & $<1$ & 4 & \\
\hline Discontinuation rate & 3 & 8 & \\
\hline Death related to AEs & 6 & 4 & \\
\hline
\end{tabular}

Abbreviations: $A E$, adverse event; $B M$, bone marrow; CLL, chronic lymphocytic leukemia; CR, complete response; MRD, minimal residual disease; NR, not reported ORR, overall response rate; OS, overall survival; PFS, progression-free survival. 
Obinutuzumab chemoimmunotherapy also resulted in higher levels of grade 3 or higher cytopenias, particularly, thrombocytopenia, and again, this was most notable with the first cycle. Likewise, tumor lysis syndrome was higher with G-CLB vs R-CLB; however, this led to only one treatment discontinuation and no more deaths were related to adverse events for G-CLB than the other groups. ${ }^{14}$

\section{Safety and tolerability}

Overall, obinutuzumab is a tolerable mAb with a toxicity profile similar to rituximab, an agent commonly used in the treatment of CLL. In the CLL11 study, IRRs were the most common AEs and led to treatment discontinuation in $7 \%$ of patients in the G-CLB arm compared to $<1 \%$ in the R-CLB arm. However, at completion of the study, it is now clear that IRRs are exceedingly rare after cycle 1 . The higher discontinuation rate in the CLL11 study compared to the Phase I/II studies of obinutuzumab is likely related from the older, frailer population and the fact that these patients were previously untreated and would have been considered to have alternate treatment options available to them. Preliminary safety data from the Phase IIIb GREEN study of obinutuzumab alone or in combination with bendamustine, fludarabine plus cyclophosphamide, or chlorambucil showed a similar safety profile from previous reports with a lower proportion of grade $\geq 3$ IRRs. ${ }^{59}$ It has been postulated that IRRs may be related to cytokines released from malignant $\mathrm{B}$ cells as they are targeted by the anti-CD20 mAb, explaining a higher frequency of IRRs with obinutuzumab compared to rituximab given the higher potency of this Type II mAb and its resultant rapid B-cell depletion. However, direct correlation between cytokine levels and IRR incidence and/or severity has not been proven. ${ }^{48,60}$ No clear predictive factors for severe IRRs were elicited in the CLL11 study, making it necessary to anticipate such reactions in all patients. An exploratory analysis of CLL11 patients was conducted. IRR risk factors were identified including treatment received (GA101 $>$ R) being the greatest risk along with other parameters such as tumor burden, target antigen expression, and $\mathrm{FC} \gamma \mathrm{R}$ gene polymorphisms. ${ }^{61}$ The hypothesis is that the glycoengineering of the antibody and the stronger activation of innate immune cells (via FC $\gamma \mathrm{R}$ ) may contribute to the increase in IRRs noted with obinutuzumab compared to rituximab. Overall, strategies were implemented in CLL11 to reduce IRR rates and severity including dividing the dose of the first infusion as well as slowing infusion rates and mandating premedications. ${ }^{14,46}$ Given the small number of patients included in the CLL11 study after these changes, the authors did not have the power to report if the changes ameliorated the incidence of IRRs.

Additional AEs of obinutuzumab include cytopenias, namely, neutropenia and thrombocytopenia, as well as infections. Less than $15 \%$ of grade 3-5 infections occurred in CLL11 with no significant difference between the three treatment groups, despite a higher incidence of grade 3-4 neutropenia in the G-CLB arm. ${ }^{14}$ Though no unusual infections were reported in the CLL11 study, a recent case of an invasive fungal infection was reported using obinutuzumab monotherapy in a heavily pretreated refractory CLL patient, ${ }^{62}$ and cases of progressive multifocal leukoencephalopathy and hepatitis $\mathrm{B}$ reactivation have also been reported similar to other novel anti-CD20 mAbs after more patients have been exposed. ${ }^{47}$ The lack of detection of unusual or invasive infections in the CLL11 study relates to the patient population as multiply pretreated patients and refractory CLL patients have significantly higher risks of invasive infections than previously untreated patients. To date, no unusual AEs have been reported with obinutuzumab, and there were no differences between the obinutuzumab and rituximab chemoimmunotherapy arms in terms of the development of $\geq 1$ malignant, benign, or unspecified neoplasm 6 months postinitiation of therapy. ${ }^{14}$ Longer follow-up is required to screen for potential rare late AEs. There is a black box warning for the use of obinutuzumab in patients with a previous history of hepatitis B infection, given the risk of hepatitis B reactivation. This risk exists in patients with detectable hepatitis B surface antigen and also in patients without detectable surface antigen but with detectable hepatitis B core antibody, which is evidence of past infection. Reactivation of hepatitis B can occur during therapy or in the several months preceding therapy, and so careful attention should be paid even after discontinuation of drug, and all patients at risk of reactivation should be treated with antiviral agents to prevent this complication. The diagnosis of progressive multifocal leukoencephalopathy is much more difficult than hepatitis reactivation, and it is also more difficult to identify at-risk patients. Any patient who experiences significant neurological deterioration following treatment with obinutuzumab should be assessed by a neurologist and all immune-suppressing agents should be discontinued.

In the CLL11 study, based on the global health status scale, quality of life did not deteriorate during either rituximab or obinutuzumab therapy compared to therapy with chlorambucil alone. ${ }^{14}$ This lack of significant toxicity with improved efficacy over rituximab suggests that obinutuzumab is an appropriate therapy in CLL patients with comorbidities. 
Table 3 Future studies of obinutuzumab (GAIOI) in CLL

\begin{tabular}{|c|c|c|c|c|}
\hline Clinical trial & Study design & Population & Regimen & Status \\
\hline $\begin{array}{l}\text { NCTOI } 300247 \\
\text { (GALTON) }\end{array}$ & $\begin{array}{l}\text { Phase lb, multicenter, } \\
\text { nonrandomized, open label }\end{array}$ & Untreated CLL & $\mathrm{GAIOI}+\mathrm{B}$ or FC & $\begin{array}{l}\text { Ongoing, recruitment } \\
\text { complete }\end{array}$ \\
\hline $\begin{array}{l}\text { NCTOI } 4 \mid 4205 \\
\text { (GAGE) }\end{array}$ & $\begin{array}{l}\text { Phase II, multicenter, } \\
\text { randomized, open label }\end{array}$ & Untreated CLL & $\begin{array}{l}\text { GAIOI (I,000 mg vs } \\
2,000 \mathrm{mg})\end{array}$ & $\begin{array}{l}\text { Ongoing, recruitment } \\
\text { complete }\end{array}$ \\
\hline NCT0I68099I & $\begin{array}{l}\text { Phase I, multicenter, } \\
\text { nonrandomized, open label }\end{array}$ & $\begin{array}{l}\text { Relapsed/refractory CLL } \\
\left(\mathrm{CD} 20^{+} \mathrm{NHL}\right)\end{array}$ & Multiple doses GAI0I & $\begin{array}{l}\text { Ongoing, recruitment } \\
\text { complete }\end{array}$ \\
\hline NCT0I 685892 & $\begin{array}{l}\text { Phase lb, multicenter, } \\
\text { nonrandomized, open label }\end{array}$ & $\begin{array}{l}\text { Untreated or relapsed/ } \\
\text { refractory CLL }\end{array}$ & $\begin{array}{l}\text { GAIOI + ABT-199 } \\
(\text { GDC-199) }\end{array}$ & Recruiting \\
\hline NCT02229422 & Phase Ib/Il, open label & $\begin{array}{l}\text { Untreated and relapsed/ } \\
\text { refractory CLL }\end{array}$ & GAI0I + HDMP & Recruiting \\
\hline NCT02I 00852 & $\begin{array}{l}\text { Phase I/llb, multicenter, } \\
\text { open label }\end{array}$ & CLL patients (not defined) & $\begin{array}{l}\text { GAIOI + TGR-I202 (PI3Ki + } \\
\text { CLB) }\end{array}$ & Recruiting \\
\hline NCT0207I 225 & $\begin{array}{l}\text { Phase II, nonrandomized, } \\
\text { open label }\end{array}$ & Refractory/relapsed CLL & $\mathrm{GAIOI}+\mathrm{B}$ & Recruiting \\
\hline $\begin{array}{l}\text { NCTOI } 905943 \\
\text { (GREEN) }\end{array}$ & $\begin{array}{l}\text { Phase Illb, multicenter, } \\
\text { nonrandomized, open label }\end{array}$ & $\begin{array}{l}\text { Untreated or relapsed/ } \\
\text { refractory CLL }\end{array}$ & $\begin{array}{l}\text { GAIOI or GAIOI + FC, } \\
\text { GAIOI + B, GAIOI + CLB }\end{array}$ & Recruiting \\
\hline NCT02264574 & $\begin{array}{l}\text { Phase III, multicenter, } \\
\text { randomized, open label }\end{array}$ & Untreated CLL & $\begin{array}{l}\text { Ibrutinib + GAI0I vs } \\
\text { GAI0I + CLB }\end{array}$ & Recruiting \\
\hline NCT0I 644253 & $\begin{array}{l}\text { Phase lb, nonrandomized, } \\
\text { open label }\end{array}$ & $\begin{array}{l}\text { Untreated and relapsed/ } \\
\text { refractory CLL }\end{array}$ & $\begin{array}{l}\text { TRU-016 + R vs TRU-016+ } \\
\text { GAI0I }\end{array}$ & Recruiting \\
\hline NCT02I00852 & $\begin{array}{l}\text { Phase I, multicenter, } \\
\text { open label }\end{array}$ & CLL (not defined) & TGR-I202 + CLB + GAI0I & Recruiting \\
\hline NCT02292225 & $\begin{array}{l}\text { Phase I, nonrandomized, } \\
\text { open label }\end{array}$ & $\begin{array}{l}\text { CLL relapsed/refractory } \\
\text { to BTKi therapy }\end{array}$ & Duvelisib (IPI- I45) + GAI0I & Pending \\
\hline NCT022969I8 & $\begin{array}{l}\text { Phase I, nonrandomized, } \\
\text { open label }\end{array}$ & $\begin{array}{l}\text { Untreated and relapsed/ } \\
\text { refractory CLL }\end{array}$ & ACP-196+ GAI0I & Pending \\
\hline NCT0I980875 & $\begin{array}{l}\text { Phase III, randomized, } \\
\text { open label }\end{array}$ & Untreated CLL & $\begin{array}{l}\text { Idelalisib + GAI0I vs } \\
\text { GAI0I + CLB }\end{array}$ & Pending \\
\hline NCT02242942 & $\begin{array}{l}\text { Phase III, multicenter, } \\
\text { randomized, open label }\end{array}$ & Untreated CLL & $\begin{array}{l}\text { GAIOI + ABT-199 } \\
(\text { GDC-199) vs GAIOI + CLB }\end{array}$ & Pending \\
\hline NCT02225275 & Interventional, open label & Relapsed/refractory CLL & $\mathrm{GAIOI}+\mathrm{L}$ & Pending \\
\hline NCT023I5768 & Phase I/II, open label & Untreated CLL & GAI0I + Ibrutinib & Pending \\
\hline
\end{tabular}

Abbreviations: B, bendamustine; BTKi, Bruton tyrosine kinase inhibitor; CLB, chlorambucil; CLL, chronic lymphocytic leukemia; FC, fludarabine plus cyclophosphamide; HDMP, high-dose methylprednisone; L, lenalidomide; NHL, non-Hodgkin lymphoma; PI3Ki, phosphatidylinositol-3 kinase inhibitor; R, rituximab.

\section{Conclusion}

Despite the success of rituximab, CLL remains an incurable disease with chemoimmunotherapy and there has been continued interest in the development of better anti-CD20 mAbs and other novel therapies for CLL. The majority of CLL patients are not eligible for fludarabine plus cyclophosphamide therapy because of advanced age and/or comorbidities. ${ }^{3,63}$

Obinutuzumab is a highly effective and well-tolerated glycoengineered Type II anti-CD20 mAb. In preclinical studies, it has shown improved antibody-dependent cellular cytotoxicity and DCD with lower CDC compared to Type I antibodies. Obinutuzumab has moderate efficacy as monotherapy in early phase studies but impressive efficacy as chemoimmunotherapy in previously untreated CLL patients with comorbidities. Results of the CLL11 study illustrate that obinutuzumab-CLB improves OS when compared to CLB monotherapy, the first demonstration of an OS advantage in previously untreated, less fit patients. Obinutuzumab-CLB also results in a clinically meaningful advantage in PFS compared to both CLB monotherapy and R-CLB therapy. Importantly, obinutuzumab's safety profile is similar to rituximab's, with the most frequent $\mathrm{AE}$ being IRRs during the first infusion, which can be managed and do not recur in subsequent cycles. ${ }^{14}$

Ongoing studies in both the frontline and salvage setting for CLL are anticipated and outlined in Table 3. A Phase IIIb multicenter trial will evaluate obinutuzumab monotherapy vs obinutuzumab chemoimmunotherapy with FC, B, or CLB for both untreated and relapsed/refractory CLL (GREEN Study: NCT 01905943). Additionally, the safety and efficacy of obinutuzumab in combination with the Bcl-2 inhibitor, ABT-199 (NCT 01685892), will be evaluated for both previously untreated and relapsed/refractory CLL patients 
and an additional study will compare this to obinutuzumab/ chlorambucil chemoimmunotherapy (NCT02242942). Overall, the challenge with the multitude of newly available therapies in CLL is knowing how to offer the safest and most effective combination therapy. New CLL treatment strategies are being proposed, which include a sequential triple-therapy (triple "T") protocol with aims of offering tailored, targeted, and total eradication of MRD. For such treatment, monoclonal antibodies like obinutuzumab with its potent effect on MRD are hypothesized to be integral parts of both induction therapy and MRD-tailored maintenance therapy. ${ }^{64,65}$

Current evidence supports the use of obinutuzumab in chemoimmunotherapy for previously untreated CLL patients with comorbidities. Further evaluation of this mAb is warranted especially in the context of the expanding array of novel agents. The potential for combination of obinutuzumab with other novel agents, such as the kinases or Bcl-2 inhibitors, provides another avenue of research that may further improve response rates and remissions for CLL patients.

\section{Author contributions}

Both authors contributed toward data acquisition, writing and revising of the manuscript and agree to be accountable for all aspects of the work.

\section{Disclosure}

Carolyn Owen has received honoraria, acted as a consultant, and participated in advisory boards for Hoffman La-Roche. No funding was provided for this study.

\section{References}

1. Siegel R, Naishadham D, Jemal A. Cancer statistics, 2013. CA Cancer J Clin. 2013;63(1):11-30.

2. Howlander N, Noone AM, Krapcho M, et al. (editors). SEER Cancer Statistics Review 1975-2011. Bethesda, MD: National Cancer Institute; April 2014. Available from: http://seer.cancer.gov/csr/1975_2011/, based on November 2013 SEER data submission, posted to the SEER web site.

3. Hallek M. Chronic lymphocytic leukemia: 2013 update on diagnosis, risk stratification and treatment. Am J Hematol. 2013;88(9):803-816.

4. Hallek M, Cheson BD, Catovsky D, et al; International Workshop on Chronic Lymphocytic Leukemia. Guidelines for the diagnosis and treatment of chronic lymphocytic leukemia: a report from the International Workshop on Chronic Lymphocytic Leukemia updating the National Cancer Institute-Working Group 1996 guidelines. Blood. 2008; 111(12):5446-5456.

5. Gupta NK, Andreadis C. New meets old: a case study and review of novel therapeutics for the treatment of CLL in older patients. $J$ Natl Compr Canc Netw. 2014;12(10):1371-1375.

6. Eichhorst B, Goede V, Hallek M. Treatment of elderly patients with chronic lymphocytic leukemia. Leuk Lymphoma. 2009;50(2):171-178.

7. Shanafelt T. Treatment of older patients with chronic lymphocytic leukemia: key questions and current answers. Hematology Am Soc Hematol Educ Program. 2013;2013:158-167.
8. Shah N, Tam C, Seymour J, Rule S. How applicable is fludarabine, cyclophosphamide and rituximab to the elderly? Leuk Lymphoma. 2014:1-29.

9. Hainsworth JD, Litchy S, Barton JH, et al. Single-agent rituximab as first-line and maintenance treatment for patients with chronic lymphocytic leukemia or small lymphocytic lymphoma: a phase II trial of the Minnie Pearl Cancer Research Network. J Clin Oncol. 2003;21(9): $1746-1751$.

10. Hallek M, Fischer K, Fingerle-Rowson G, et al; International Group of Investigators, German Chronic Lymphocytic Leukaemia Study Group. Addition of rituximab to fludarabine and cyclophosphamide in patients with chronic lymphocytic leukaemia: a randomised, open-label, phase 3 trial. Lancet. 2010;376:1164-1174.

11. Hillmen P, Gribben JG, Follows GA, et al. Rituximab plus chlorambucil as first-line treatment for chronic lymphocytic leukemia: final analysis of an open-label phase II study. J Clin Oncol. 2014;32(12):1236-1241.

12. Cartron G, Trappe RU, Solal-Céligny P, Hallek M. Interindividual variability of response to rituximab: from biological origins to individualized therapies. Clin Cancer Res. 2011;17(1):19-30.

13. Lemery SJ, Zhang J, Rothmann MD, et al. US Food and Drug Administration approval: ofatumumab for the treatment of patients with chronic lymphocytic leukemia refractory to fludarabine and alemtuzumab. Clin Cancer Res. 2010;16(17):4331-4338.

14. Goede V, Fischer K, Busch R, et al. Obinutuzumab plus chlorambucil in patients with CLL and coexisting conditions. N Engl J Med. 2014; 370(12):1101-1110.

15. Glennie MJ, French RR, Cragg MS, Taylor RP. Mechanisms of killing by anti-CD20 monoclonal antibodies. Mol Immunol. 2007; 44(16):3823-3837.

16. Cragg MS, Morgan SM, Chan HT, et al. Complement-mediated lysis by anti-CD20 mAb correlates with segregation into lipid rafts. Blood. 2003;101(3):1045-1052.

17. Kennedy AD, Beum PV, Solga MD, et al. Rituximab infusion promotes rapid complement depletion and acute $\mathrm{CD} 20$ loss in chronic lymphocytic leukemia. J Immunol. 2004;172(5):3280-3288.

18. Cragg MS, Glennie MJ. Antibody specificity controls in vivo effector mechanisms of anti-CD20 reagents. Blood. 2004;103(7):2738-2743.

19. Racila E, Link BK, Weng WK, et al. A polymorphism in the complement component C1qA correlates with prolonged response following rituximab therapy of follicular lymphoma. Clin Cancer Res. 2008; 14(20):6697-6703.

20. Bannerji R, Kitada S, Flinn IW, et al. Apoptotic-regulatory and complement-protecting protein expression in chronic lymphocytic leukemia: relationship to in vivo rituximab resistance. J Clin Oncol. 2003;21(8):1466-1471.

21. Dalle S, Reslan L, Besseyre de Horts T, et al. Preclinical studies on the mechanism of action and the anti-lymphoma activity of the novel anti-CD20 antibody GA101. Mol Cancer Ther. 2011;10(1):178-185.

22. Bologna L, Gotti E, Manganini M, et al. Mechanism of action of type II, glycoengineered, anti-CD20 monoclonal antibody GA101 in B-chronic lymphocytic leukemia whole blood assays in comparison with rituximab and alemtuzumab. J Immunol. 2011;186(6):3762-3769.

23. Di Gaetano N, Cittera E, Nota R, et al. Complement activation determines the therapeutic activity of rituximab in vivo. J Immunol. 2003; 171(3):1581-1587.

24. Cittera E, Leidi M, Buracchi C, et al. The CCL3 family of chemokines and innate immunity cooperate in vivo in the eradication of an established lymphoma xenograft by rituximab. J Immunol. 2007;178(10):6616-6623.

25. Uchida J, Hamaguchi Y, Oliver JA, et al. The innate mononuclear phagocyte network depletes B lymphocytes through Fc receptordependent mechanisms during anti-CD20 antibody immunotherapy. J Exp Med. 2004;199(12):1659-1669.

26. Herter S, Herting F, Mundigl O, et al. Preclinical activity of the type II CD20 antibody GA101 (obinutuzumab) compared with rituximab and ofatumumab in vitro and in xenograft models. Mol Cancer Ther. 2013;12(10):2031-2042. 
27. Niederfellner G, Lammens A, Mundigl O, et al. Epitope characterization and crystal structure of GA101 provide insights into the molecular basis for type I/II distinction of CD20 antibodies. Blood. 2011;118(2):358-367.

28. Mössner E, Brünker P, Moser S, et al. Increasing the efficacy of CD20 antibody therapy through the engineering of a new type II anti-CD20 antibody with enhanced direct and immune effector cell-mediated B-cell cytotoxicity. Blood. 2010;115(22):4393-4402.

29. Klein C, Lammens A, Schäfer W, et al. Epitope interactions of monoclonal antibodies targeting CD20 and their relationship to functional properties. MAbs. 2013;5(1):22-33.

30. Kern DJ, James BR, Blackwell S, Gassner C, Klein C, Weiner GJ. GA101 induces NK-cell activation and antibody-dependent cellular cytotoxicity more effectively than rituximab when complement is present. Leuk Lymphoma. 2013;54(11):2500-2505.

31. Golay J, Da Roit F, Bologna L, et al. Glycoengineered CD20 antibody obinutuzumab activates neutrophils and mediates phagocytosis through CD16B more efficiently than rituximab. Blood. 2013; 122(20):3482-3491.

32. Alduaij W, Ivanov A, Honeychurch J, et al. Novel type II anti-CD20 monoclonal antibody (GA101) evokes homotypic adhesion and actindependent, lysosome-mediated cell death in B-cell malignancies. Blood. 2011;117(17):4519-4529.

33. Honeychurch J, Alduaij W, Azizyan M, et al. Antibody-induced nonapoptotic cell death in human lymphoma and leukemia cells is mediated through a novel reactive oxygen species-dependent pathway. Blood. 2012;119(15):3523-3533.

34. Jak M, van Bochove GG, Reits EA, et al. CD40 stimulation sensitizes CLL cells to lysosomal cell death induction by type II anti-CD20 mAb GA101. Blood. 2011;118(19):5178-5188.

35. Owen C, Stewart DA. Obinutuzumab for the treatment of lymphoproliferative disorders. Expert Opin Biol Ther. 2012;12(3):343-351.

36. Pedersen AE, Jungersen MB, Pedersen CD. Monocytes mediate shaving of B-cell-bound anti-CD20 antibodies. Immunology. 2011;133(2): 239-245.

37. Beum PV, Lindorfer MA, Taylor RP. Within peripheral blood mononuclear cells, antibody-dependent cellular cytotoxicity of rituximabopsonized daudi cells is promoted by NK cells and inhibited by monocytes due to shaving. J Immunol. 2008;181(4):2916-2924.

38. Beers SA, French RR, Chan HT, et al. Antigenic modulation limits the efficacy of anti-CD20 antibodies: implications for antibody selection. Blood. 2010;115(25):5191-5201.

39. Boyd RS, Jukes-Jones R, Walewska R, Brown D, Dyer MJS, Cain K. Protein profiling of plasma membranes defines aberrant signaling pathways in mantle cell lymphoma. Mol Cell Proteomics. 2009;8(7): 1501-1515.

40. Klepfish A, Gilles L, Ioannis K, Rachmilewitz EA, Schattner A. Enhancing the action of rituximab in chronic lymphocytic leukemia by adding fresh frozen plasma: complement/rituximab interactions and clinical results in refractory CLL. Ann N Y Acad Sci. 2009;1173: 865-873.

41. Cartron G. Therapeutic activity of humanized anti-CD20 monoclonal antibody and polymorphism in IgG Fc receptor FcyRIIIa gene. Blood. 2002;99(3):754-758.

42. Koene HR, Kleijer M, Algra J, Roos D, von dem Borne AE, de Haas M. Fc $\gamma$ RIIIa-158V/F polymorphism influences the binding of IgG by natural killer cell Fc $\gamma$ RIIIa, independently of the Fc $\gamma$ RIIIa-48L/R/H phenotype. Blood. 2014:1109-1114.

43. Olejniczak SH, Hernandez-Ilizaliturri FJ, Clements JL, Czuczman MS. Acquired resistance to rituximab is associated with chemotherapy resistance resulting from decreased Bax and Bak expression. Clin Cancer Res. 2008;14(5):1550-1560.

44. Hiraga J, Tomita A, Sugimoto T, et al. Down-regulation of CD20 expression in B-cell lymphoma cells after treatment with rituximab-containing combination chemotherapies: its prevalence and clinical significance. Blood. 2009; 113(20):4885-4893.
45. Owen C, Stewart DA. Obinutuzumab for B-cell malignancies. Expert Opin Biol Ther. 2014;14(8):1197-1205.

46. Shah A. Obinutuzumab: a novel anti-CD20 monoclonal antibody for previously untreated chronic lymphocytic leukemia. Ann Pharmacother. 2014;48(10):1356-1361.

47. Kakkar AK, Balakrishnan S. Obinutuzumab for chronic lymphocytic leukemia: promise of the first treatment approved with breakthrough therapy designation. J Oncol Pharm Pract. 2014:1-6.

48. Cartron G, de Guibert S, Dilhuydy MS, et al. Obinutuzumab (GA101) in relapsed/refractory chronic lymphocytic leukemia: final data from the phase 1/2 GAUGUIN study. Blood. 2014;124(14):2196-2202.

49. Flynn JM, Byrd JC, Kipps TJ, et al. Obinutuzumab (GA101) 1,000 mg versus 2,000 mg in patients with chronic lymphocytic leukemia (CLL): results of the phase II GAGE (GAO4768g) trial. J Clin Oncol. 2014;32(5s):abstract7083.

50. Patz M, Isaeva P, Forcob N, et al. Comparison of the in vitro effects of the anti-CD20 antibodies rituximab and GA101 on chronic lymphocytic leukaemia cells. Br J Haematol. 2011;152(3):295-306.

51. Herting F, Friess T, Bader S, et al. Enhanced anti-tumor activity of the glycoengineered type II CD20 antibody obinutuzumab (GA101) in combination with chemotherapy in xenograft models of human lymphoma. Leuk Lymphoma. 2014;55(9):2151-5160.

52. Illidge T, Cheadle EJ, Donaghy $\mathrm{C}$, Honeychurch J. Update on obinutuzumab in the treatment of B-cell malignancies. Expert Opin Biol Ther. 2014;14(10):1507-1517.

53. Salles G, Morschhauser F, Lamy T, et al. Phase 1 study results of the type II glycoengineered humanized anti-CD20 monoclonal antibody obinutuzumab (GA101) in B-cell lymphoma patients. Blood. 2012;119(22):5126-5132.

54. Sehn LH, Assouline SE, Stewart DA, et al. A phase 1 study of obinutuzumab induction followed by 2 years of maintenance in patients with relapsed CD20-positive B-cell malignancies. Blood. 2012; 119(22):5118-5125.

55. Brown JR, O'Brien S, Kingsley CD, et al. Safety and efficacy obinutuzumab (GA101) with fludarabine/cyclophosphamide (G-FC) or bendamustine (G-B) in the initial therapy of patients with chronic lymphocytic leukemia (CLL): results of the phase 1b Galton trial (GA04779g). Blood. 2013;122(21):523.

56. Eichhorst BF, Busch R, Stilgenbauer S, et al; German CLL Study Group (GCLLSG). First-line therapy with fludarabine compared with chlorambucil does not result in a major benefit for elderly patients with advanced chronic lymphocytic leukemia. Blood. 2009;114(16): 3382-3391.

57. Böttcher S, Hallek M, Ritgen M, Kneba M. The role of minimal residual disease measurements in the therapy for CLL: is it ready for prime time? Hematol Oncol Clin North Am. 2013;27(2):267-288.

58. Böttcher S, Ritgen M, Fischer K, et al. Minimal residual disease quantification is an independent predictor of progression-free and overall survival in chronic lymphocytic leukemia: a multivariate analysis from the randomized GCLLSG CLL8 trial. J Clin Oncol. 2012;30(9): 980-988.

59. Bosch F, Illmer T, Turgut M, et al. Preliminary safety results from the phase IIIb GREEN study of obinutuzumab (GA101) alone or in combination with chemotherapy for previously untreated or relapsed/refractory chronic lymphocytic leukemia (CLL). Blood. 2014;124(21):3345.

60. Freeman CL, Morschhauser F, Sehn LH, et al. Pattern of cytokine release in patients with chronic lymphocytic leukemia treated with obinutuzumab and possible relationship with development of infusion related reactions (IRR). Blood. 2014;124(21):4674.

61. Freeman CL, Dixon M, Houghton R, et al. Risk factors associated with the development of infusion-related reactions in patients with chronic lymphocytic leukaemia treated with anti-CD20 monoclonal antibodies: analysis of the CLL11 study dataset. Blood. 2014;124(21):3339.

62. Tse E, Leung RY, Kwong YL. Invasive fungal infections after obinutuzumab monotherapy for refractory chronic lymphocytic leukemia. Ann Hematol. 2015;94(1):165-167. 
63. Byrd JC, Jones JJ, Woyach JA, Johnson AJ, Flynn JM. Entering the era of targeted therapy for chronic lymphocytic leukemia: impact on the practicing clinician. J Clin Oncol. 2014;32(27):3039-3047.

64. Hallek M. Signaling the end of chronic lymphocytic leukemia: new frontline treatment strategies. Blood. 2013;122(23):3723:3734.
65. Pallasch CP, Hallek M. Incorporating targeted agents into future therapy of chronic lymphocytic leukemia. Semin Hematol. 2014;51(3):235-248.

\section{Publish your work in this journal}

Biologics: Targets \& Therapy is an international, peer-reviewed journal focusing on the patho-physiological rationale for and clinical application of Biologic agents in the management of autoimmune diseases, cancers or other pathologies where a molecular target can be identified. This journal is indexed on PubMed Central, CAS, EMBase, Scopus

\section{Dovepress}

and the Elsevier Bibliographic databases. The manuscript management system is completely online and includes a very quick and fair peerreview system, which is all easy to use. Visit http://www.dovepress com/testimonials.php to read real quotes from published authors. 